\section{Chemical Carcinogenesis and Cancers}

By W. C. Hueper and W. D. Conway. American

Lecture Series No. 585, Pp. xx+744. Springfield, Illinois: Charles C. Thomas, 1965. \$20.

There is a continued rise in the production and consumption of carcinogenic chemicals. The prorequisite of prophylactic and preventive measures in the control of any disease is the availability of adequate information on the causes of the disease and on the sources and opportunities of exposure to such causes. Efforts to prevent chemically induced cancers have in the past been limited by the absence of a comprehensive co-ordinated and critical analysis of the information already available. This book goes a long way towards supplying such information. The experimental aspects and epidemiology of chemically induced cancers are considered in detail and the legal and social implications discussed. The known and suspected chemical carcinogens are fully represented. There are useful tables of deaths in different countries from various cancers and their distribution is illustrated by maps. The importance of environmental, socio-economic and occupational factors is well brought out. The middle portion of this book is concerned with technical aspects of planning and conducting investigation in chemical carcinogenesis, the protection of workers and the care of experimental animals, while the latter part deals with the prevention of environmental cancer, the control of occupational hazards and legal liability. The responsibilities of government, management and the individual are explored and standards of medical supervision suggested. The authors draw attention to the inadequacy of the present laws of compensation, in particular to the time clause which limits the presentation of claims to specified periods after cessation of exposure to the carcinogen. While these periods may be adequate for meeting the conditions associated with the great majority of occupational diseases they are insufficient in regard to occupational cancers, which may develop twenty years or more after exposure has ceased. We may also add the need for adequate follow-up and the wider use of cytological techniques to enable a malignant change to be detected at a treatable stage. The bibliography is extensive.

\section{Problems of the Aged}

Edited by Clyde B. Vedder, Ph.D., and AnNette S. LEFKOvITZ. Pp. xvii + 259. Springfield, Illinois : Charles C. Thomas 1964. \$7.50.

This book is edited jointly by a professor of sociology and a professor of nursing education. It consists of articles reprinted from various American journals, mainly Geriatrics and the American Journal of Nursing. The contributors for the most part are doctors but the nursing and social work professions are also represented.

The social and psychological aspects are well covered and there are some revealing articles on American nursing homes. There is even a militant article by the President of the American Medical Association attacking the Medicare programme. An article by Edwin T. Arnold on the prinicples of geriatrics contains some wise advice but perhaps the most impressive contribution is by Frederick A. Whitehouse on the psychological problems associated with strokes.

Inevitably the book abounds in generalities and there are few reports of original research, though the report by Doris Schwartz on errors in the self administration of medicines by elderly people is a welcome exception.

Where the book does succeed very well is in conveying the essential flavour of geriatric work. Although presumably designed for nurses, Problems of the Aged would appear to be more suitable for doctors. It can be recommended as likely to promote a better understanding of the medical and social problems of the elderly.

\section{Autoimmunity and Disease}

L. E. Glynn and E. J. Holborow. Pp. vii + 420, illustrated. Oxford: Blackwell Scientific Publications. 1965. 60s.

The concept of autoimmunity or autoallergy or autoimmunopathy is upon us whether we like it or not; and the term autoimmunity is also very much with us because of common daily usage. If we can accept the concept and the term-as we must if we are to be "with it" in 1966-then this monograph is a joy to read. The first five chapters present the concept and thereafter every system, organ and tissue of the body is analysed from this viewpoint. They include the joints, nervous system, adrenal and thyroid glands, alimentary tract, kidney, liver, testis, eye, skin, blood and heart. This means a specialist chapter for every discipline and for every postgraduate. No matter how specialised he may have become, he should read them all.

This particular branch of immunology is now proliferating so rapidly that even this up-to-date monograph must have gone to press before the beautiful demonstration of non-organ specific mito- 8 chondrial circulating antibodies which help to segregate primary biliary cirrhosis as a well-defined autoimmune reaction. But this will undoubtedly appear in a second edition. Until it appears no postgraduate should be without the first edition.

\section{Assessment of Cerebral Palsy}

K. S. Holt. Pp. vi +214 illustrated. London: Lloyd Luke. 1965. 40s.

This is the first of two volumes by Dr. Holt on the assessment of cerebral palsy. It concentrates on motor function. The book is divided into broadly three sections. The first covers muscle function generally, and includes the assessment of muscle power, of the range of joint movements and of muscle tone. The second section deals with locomotion, and there are chapters on the techniques for assessment of this function, on posture and balance and on gait and abnormal movements. The third section is devoted to hand function and manipulative skills.

I enjoyed the latter section most. It is concise, lucid and extremely readable. The data is well presented and the photographic illustrations are excellent. The other two sections also contain a wealth of useful information. However, in a book of this nature, it is always a difficult task to present data in a sufficiently simple manner to be acceptable to the person without much theoretical training, and at the same time to be sufficiently critical for the specialist in the field. It is hard to please everybody.

I found some parts (e.g. on muscle activity and length, p.17) over-simplified and repetitive. Others (e.g. the elucidation of spasticity, p.75) were not at all clear, and would have benefited from more detailed discussion and explanation. I also see no advantage in having definitions for such terms as 
'athetosis' and 'ataxia', which do not conform to general neurological teaching.

The illustrations throughout are well selected and the captions adequate. The inclusion of representative short case histories adds to the interest of the text. The references are rather limited in number, but contain a number of recent reviews on the respective topics. In compiling this book, Dr. Holt has drawn not only on his own extensive experience in the care of handicapped children, but also on the experience of the physiotherapist, the occupational therapist, the psychologist and other members of the team. This book will be welcomed by all who are concerned with the management of cerebral palsied children.

\section{NEW EDITIONS}

\section{Clinical Scalar Electrocardiography}

B. S. Lipman and E. Massie, 5th edition, Pp. 634 illustrated. Chicago: Year Book Medical Publishers. London: Lloyd-Luke. 1965. 83s.

Dr. Lipman and Dr. Massie have set out to produce a manual on scalar electrocardiography which takes the student from first principles to a working plane in interpretation, using a physiological basis and a detailed study of heart activation. After 634 pages and a profusion of clear diagrams they succeed -at a price.

In the preface the authors state "the first edition was a simple concise monograph for the beginner, with each succeeding edition the book has become more complicated". The fifth edition is no exception - but for the advanced student it gives a reasoned, scientific approach to the interpretation of scalar electrocardiograms, "by distilling vector, panoramic deductive and standard pattern methods." The large section of illustrated electrocardiograms is comprehensive and beautifully produced.

\section{Recent Advances in Paediatrics, 3rd edition}

Edited by Douglas Gairdner. Pp. viii +349 ; 86 figures + tables. London: J. \& A. Churchill. 1965. 60s.

The latest publication in this well-known and popular series surpasses its predecessors. Here we have an outstanding collection of reviews and essays of contemporary interest and Dr. Douglas Gairdner, $\bar{z}$ who again edits the volume, must be congratulated $\stackrel{\mathbb{Q}}{\varrho}$ both on his selection of topics and choice of $\frac{\varrho}{c}$ specialist contributors. The publishers deserve praise, $\rightarrow$ too, for the attractive way in which the book is $\overrightarrow{\vec{ज}}$ presented; also for supporting, again, a production $\stackrel{\oplus}{\rightarrow}$ of this kind. At least half the work is devoted to recent advances in neonatal paediatrics and because $\bar{\sigma}$ of this emphasis the book can be recommended not $\overline{\bar{\sigma}}$ only to paediatricians and intending specialists in this $\vec{\nabla}$ field but to all doctors whose practice brings them into contact with the newborn baby.

Atlas of Human Anatomy. Vols. 1, 2, and 3. 17th. edition, 2nd English edition. By FERENC KISS, M.D., and Janos Szentagothai, M.D. Oxford, London, New York, etc., Pergamon Press. 1964. £6 6s.

Most pre-clinical students learn their anatomy $\overrightarrow{\mathrm{N}}$ from the body and from dissecting manuals. From time to time they groan beneath the weight of the heavier textbooks or gloat over the glossy colours of $\mathrm{F}$ an atlas. Usually, the atlas is returned to the shelf $\mathrm{N}$ with a sigh because few students can afford to buy $\overrightarrow{1}$ one. This present atlas is in three volumes which makes it easy to handle, and costs only six guineas $\subseteq$ for the set, which, considering the high standard of production, is cheap. Most of the illustrations are $z$ bold, beautifully coloured, and clearly labelled; a few ฏ inevitably are less attractive in colour, and the $\frac{\hat{S}}{\mathrm{~S}}$ occasional one loses impact from over-labelling. $\mathrm{OB}$ the whole, however, the volumes are a joy to handle and a pleasure to look through; the familiat systematic arrangement facilitates careful study.

The first edition of this work was published in Hungarian in 1946. Since then it has also been published in German, Russian, Bulgarian, Chinese, Spanish, and Czechoslovakian, and this is the second English edition. It is, therefore, a well tried work and the authors are to be congratulated not only on the skill of their dissections, but also on securing the services of such artistic designers and illutrators. 